\title{
BMJ Open Development and validation of a parent-proxy health-related quality of life survey for Australian First Nations children
}

\author{
Kaley Butten (D) , ${ }^{1}$ Lee Jones, ${ }^{1}$ Peter A Newcombe, ${ }^{2}$ Anne B Chang, ${ }^{3,4,5}$ \\ Jeanie K Sheffield, ${ }^{2}$ Kerry-Ann F O'Grady (D) , ${ }^{1}$ Newell W Johnson,, \\ Anna Maria Bell, ${ }^{8}$ Greggory Ross, ${ }^{8}$ Maree Toombs ${ }^{9}$
}

To cite: Butten $\mathrm{K}$, Jones $\mathrm{L}$, Newcombe PA, et al. Development and validation of a parent-proxy healthrelated quality of life survey for Australian First Nations children. BMJ Open 2021;11:e046007. doi:10.1136/ bmjopen-2020-046007

- Prepublication history for this paper is available online. To view these files, please visit the journal online (http://dx.doi. org/10.1136/bmjopen-2020046007).

We remember our friend and co-author.

Received 20 0ctober 2020 Accepted 23 July 2021

Check for updates

(C) Author(s) (or their employer(s)) 2021. Re-use permitted under CC BY-NC. No commercial re-use. See rights and permissions. Published by BMJ.

For numbered affiliations see end of article.

Correspondence to

Dr Kaley Butten;

kaley.butten@hdr.qut.edu.au

\section{ABSTRACT}

Objective Within Australia, Aboriginal and Torres Strait Islander (First Nations) populations perceive health and well-being differently to non-Indigenous Australians. Existing health-related quality of life (HR-QoL) measurement tools do not account for these differences. The objective of this study was to develop and validate a culturally specific parent-proxy HR-QoL measurement tool for First Nations children.

Design Scale development was informed by parents/ carers of children with a chronic illness and an expert panel. The preliminary 39 -item survey was reviewed $(n=12)$ and tested $(n=163)$ with parents/carers of First Nations children aged $0-12$ years at baseline with comparative scales: the Kessler Psychological Distress Scale, generic HR-QoL (Paediatric QoL Inventory 4.0, PedsQL ${ }^{4.0}$ ) and Spence Children's Anxiety Scale, and repeated $(n=46) 4$ weeks later. Exploratory Factor Analysis was used for scale reduction. Reliability and validity were assessed by internal consistency, test-retest, and correlations with comparison scales.

Results Items within our First Nations-Child Quality of Life (FirstNations-CQoL) were internally consistent with Cronbach's alpha coefficients of $\geq 0.7$ (quality of life, 0.808 ; patient experience, 0.880; patient support, 0.768) and overall test-retest reliability was good $(r=0.75 ; 95 \% \mathrm{Cl}$ 0.593 to 0.856 ). Convergent validity was observed with the PedsQL ${ }^{4.0}$ with Pearson's coefficients of $r=0.681$ (ages $2-4$ years); $r=0.651$ (ages 5-12 years) and with the Kessler Psychological Distress scale $(r=-0.513)$. Divergent validity against the Spence Anxiety Scale was not demonstrated. Conclusions The FirstNations-CQoL scale was accepted by the participants, reliable and demonstrated convergent validity with comparison measures. This tool requires further evaluation to determine responsiveness, its minimal important difference and clinical utility.

\section{INTRODUCTION}

Improved health-related quality of life (HRQoL) is considered a desirable patient outcome in addition to standard biomedical outcomes. Evaluated using a psychometric tool, measuring HR-QoL can provide health
Strengths and limitations of this study

- To the best of our knowledge, this study is the first to develop a culturally specific health-related quality of life metric for First Nations Australian people.

- The study's strengths include the consultative approach taken to develop and refine the concepts included in the measurement tool, and the inclusion of infants and children with different health conditions.

- The study is limited by the availability of validated psychometrics for First Nations Australian people; we were unable to determine divergent validity.

- The FirstNations-Child Quality of Life would benefit from further evaluation using other metrics, a disease-specific sample and treatment context.

professionals valuable insight into a patient's subjective health status. However, one measure does not fit all. HR-QoL is informed by culture and value systems and measures should be reflective of the population they are used with. ${ }^{1}$

Within Australia, the way Aboriginal and Torres Strait Islander (hereafter respectfully referred to as First Nations) populations perceive health and well-being is different to other Australians. ${ }^{23}$ Unlike Anglo-centric notions of health, the well-being of First Nations Australians is not an individual concept, but can be better understood in how the individual is connected to their identity, culture, spirituality, family, community and country. ${ }^{4}$ Social and historical determinants such as colonisation also play a role in how health and well-being is perceived. The colonial process has undermined the autonomy, empowerment and recognition of First Nations people and as such, experiences of health and healthcare are valued differently to those that have not experienced the same marginalisation. ${ }^{23}$ 
Angell $e t a l$ s review of available HR-QoL measures for Indigenous populations globally concluded that available tools are primarily built using Anglo-centric notions of health. As these do not adequately capture the subjective HR-QoL of Indigenous populations (including First Nations Australians), psychometric tools should be developed in cooperation with First Nations Australians in order to accurately reflect their values. ${ }^{2-6}$ To the best of our knowledge, there are no tools that have been developed or validated specifically to measure the HR-QoL of Australian First Nations adults or children. ${ }^{3}$

This study was informed by a prior qualitative investigation which aimed to understand the meaning of HR-QoL to parents and carers of Australian First Nations children with a chronic illness. The qualitative findings have been published. ${ }^{7}$ Older children are able to report their own HR-QoL but a parent-proxy report is required for young or unwell children who are unable to report for themselves. ${ }^{8}$ Understanding the parent or carer's perspectives can also provide insight into healthcare utilisation and family values regarding potential treatment options. ${ }^{8}$

In the absence of a validated HR-QoL tool for First Nations children, we developed and validated a culturally specific parent-proxy HR-QoL measurement tool for First Nations children. The First Nations-Child Quality of Life (FirstNations-CQoL) aims to reflect the values associated with the HR-QoL of First Nations Australian children from the perspective of their parents and carers. Here, we describe the procedure we used to identify items, draft the tool and test its validity.

\section{METHOD}

\section{Study design}

Development of our measurement tool, the First NationsCQoL, consisted of three stages: (A) development of a draft tool based on the findings of the qualitative study, ${ }^{7}$ (B) gathering and integrating feedback, and (C) validation of the tool using statistical techniques and comparative measures.

\section{Patient and public involvement}

The impetus for this study came from clinician-led awareness in using Western-culture-based HR-QoL for First Nations peoples. This was discussed with the First Nations Reference Group based in Darwin approximately 7 years ago. When specific funding then became available, the pursuit and facilitation of the study was endorsed by several First Nations leaders who had engaged with Prof Anne Chang in her work treating respiratory illnesses experienced by First Nations children. Both clinicians and patient families realised that the available HR-QoL measures had not been created with First Nations people and thus a novel approach was needed to capture First Nations perspectives. This study was informed by a qualitative study with First Nations parents which explored how HR-QoL should and could be measured. Additional consultation with participants was also sought in the development of the tool during stage B (gathering and integrating feedback), to ensure that participants had a say in the data collection process (with respect to which questions should be asked and the time required to participate), as well as the final product. Participants were not involved in the plans to disseminate the findings but made aware during the consent process that the findings of the study would be published in a scientific journal and presented in relevant community settings and conferences. Participants were also invited to contact the researchers if they had any questions about the study or the findings.

\section{Setting and participants}

The primary recruitment location was the Queensland Children's Hospital in Brisbane, Australia, the State's only tertiary paediatric facility. Recruitment took place across the hospital, on patient wards and in outpatient clinics. Additional recruitment took place in regional areas outside of Brisbane at primary healthcare clinics located in Toowoomba and Warwick; these centres are approximately 2 hours drive west of Brisbane.

Parents and carers of First Nations children aged 0-12 years inclusive were eligible to participate. Stage B (gathering and integrating feedback) included only parents and carers of children with a chronic health condition and recruitment was ceased for this stage once no further new feedback was obtained. Stage C (validation) included parents and carers of children with and without chronic conditions. Children were excluded if they were in the care of State services, as primary parents/carers would be unable to consent and we would be unable to determine whether the state service could be an adequate proxy for the child.

Screening of potential participants for stages B and C was supported by two hospital Indigenous Liaison officers who provided daily guidance on which families were available to approach for recruitment. The primary researcher (KB) and another research assistant approached potential participants in person in the hospital clinic waiting rooms and on the hospital wards. Participants in Toowoomba and Warwick were recruited from the clinic waiting room. The study protocol was explained verbally and through a written plain language statement and signed consent was obtained from all potential participants.

During stage B, potential participants were invited to complete the draft paper-based survey which included demographic and health-related questions about themselves and their children, as well as the associated comparison measures. The survey had additional blank space for written feedback and participants were able to provide verbal feedback to the primary researcher $(\mathrm{KB})$.

For stage C, participants had the option of completing the finalised paper-based survey or a deidentified online survey (via surveymonkey.com.au). For the paper-based survey, participants were required to consent at the time of recruitment as to whether they would agree to being contacted 4 weeks later to complete the scales again. For 
the online survey, participants were able to indicate after completing the survey online whether they consented to the follow-up survey being sent 4 weeks later. For both stages $\mathrm{B}$ and $\mathrm{C}$, assistance with understanding and/or reading the survey was offered to all participants at the time of consent. The researcher explained that participants could ask questions or receive assistance in reading and completing the material if that was their preference.

\section{Stage A: development of draft FirstNations-CQoL Item development}

Fifty-two items for the FirstNations-CQoL were obtained from our prior qualitative study that involved yarning sessions with 26 First Nations parents and carers of children aged less than 18 years who experienced a chronic condition. ${ }^{7}$ This first study explored how parents and carers perceived the concept of HR-QoL as it related to their children. Thematic analysis of the qualitative data was completed by two researchers (KB and MT), and themes derived to inform potential items on the HR-QoL tool. An 'item' refers to the concept that is used to represent the different facets of HR-QoL in the form of a question when placed into survey format.

\section{Item reduction}

The 52 items above were formatted in a document with a ranking scale to determine an item Content Validity Index (I-CVI) by an expert panel. We used Polit and Beck's method where each item could be ranked from 1 (do not use) to 4 (definitely Keep). ${ }^{9}$ Six experts independently ranked these items in accordance with Polit and Beck's method. ${ }^{9}$ These included First Nations academics, First Nations Health Workers and clinicians who work closely with First Nations Australian paediatric and adult populations. The ranking was not purposefully blinded, yet experts worked independently in their decision making. The I-CVI score was determined by summing the percentage of agreement between the panel: items were included on greater than $79 \%$ agreement and removed if less than $69 \%$ agreement, those in-between were iteratively reviewed until a resolution was achieved. ${ }^{9}$ The ranking process effectively reduced the number of items from 52 to 39 items and these were formatted into questions in a paper-based survey format with a five-point Likert-style scale for answers (never, almost never, sometimes, often, always).

\section{Materials}

The 39-item FirstNations-CQoL was then formatted and collated with the following questionnaires (the comparative scales) for stage $\mathrm{B}$, before being finalised and formatted into an additional online version for stage $\mathrm{C}$.

1. Single item HR-QoL. Participants were invited to indicate on a numerical scale from 1 (terrible) to 10 (excellent), how they would rate their child's HR-QoL.

2. The Kessler Psychological Distress Scale (KPDS). ${ }^{10}$ This is a validated 10-item scale investigating whether a person has been experiencing anxiety or depression in the past 4 weeks. The tool has been used with general Australian adults previously, and adapted versions of the scale (the Kessler 5 and 6) validated with Australian First Nations adults. ${ }^{5}$ Participants were invited to complete the Kessler 10 based on their own experiences as adults. The measure assesses parent well-being at the time of completion.

3. The Paediatric QoL Inventory $4.0\left(\right.$ PedsQL $\left.\mathrm{Q}^{4.0}\right) .{ }^{11}$ This is a validated 23-item parent-proxy measure of child HR-QoL. It has a five-point Likert-style scale $(0=$ never a problem to $4=$ almost always a problem). The PedsQL ${ }^{4.0}$ inventory has demonstrated reliability and validity and is reported to be applicable across a variety of settings, including clinical trials and research. ${ }^{11}$ The inventory caters to four age groups (2-4, 5-7, 8-12 and 13-18 years). Depending on the age of their child, parents of children aged 2-12 were invited to complete the respective measure.

4. The Spence Children's Anxiety Scale, parent version. ${ }^{12}$ This is a scale designed to measure anxiety in children. There are two versions of the scale, one for preschool children and one for school-aged children. The preschool scale consists of 28 items that ask parents to report on the frequency of which an item is true for their child. Each item is rated on a five-point scale from 0 'not at all' to 4 'very often true'. The scale has been validated for Australian children aged 2.5-6 years. ${ }^{13}$ The school-aged version consists of 44 items and has been validated for Australian children aged $6-18$ years. The parent rates on a four-point scale (never, sometimes, often or always) how often each of the items happens to their child. ${ }^{13}$

In addition to the above, sociodemographic, cultural, health and well-being information were collected by self-report.

\section{Stage B: gathering and integrating feedback}

The draft 39-item FirstNations-CQoL and related materials were disseminated to 12 participants (participants included mothers who identified as First Nations women and whose children had a chronic illness) to enquire about the appropriateness and acceptability of the tool. Participants were encouraged to provide both verbal and written feedback on the usability and applicability of the tool to First Nations HR-QoL values. Feedback on the item content specifically was encouraged, including whether items should be deleted, created, or refined. As well, feedback on the entirety of the research materials was sought.

All 12 participants who undertook the pilot study indicated that they thought that the FirstNations-CQoL was both acceptable and appropriate for use with Australian First Nations families. While we received feedback to shorten the tool if possible, the participants indicated that this was not a priority for stage $(\mathrm{C})$ validation as all the content was relevant and no items were deemed inappropriate or unacceptable. We thus retained all 39 items chosen from the item reduction process. 


\section{Stage C: statistical validation of FirstNations-CQoL}

Stage C comprised the dissemination of the tool along with the comparison measures above to participants recruited through the Queensland Children's Hospital and community clinics as described above.

\section{Sample size}

Guidelines for establishing the respondent-to-item ratio vary, 5:1 (participants: question) is suggested as the minimum. ${ }^{14}$ We aimed for a ratio of $6: 1$. We had initially anticipated no more than 21 questions to be included on the FirstNations-CQoL and as such aimed to recruit 160 participants (allowing for $20 \%$ attrition over a 4-week test-retest period) with respect to our timelines.

\section{Identification of domains}

Participant feedback and prior research ${ }^{15}$ have indicated a preference for measures that are shorter and quicker to complete. In this instance there was also an insufficient participant to item ratio to complete an exploratory factor analysis (EFA) with all 39 items. An EFA is a statistical technique that is used to summarise variables that have patterned correlations, known as latent factors. ${ }^{16}$ For HR-QoL scales, this means evaluating whether the themes that have been identified as relating to HR-QoL conceptually, also correlate together statistically into factors or what is commonly termed 'domains'. This technique is best performed with a large respondent-toitem ratio. ${ }^{16}$ Thus, it was decided to reduce items prior to conducting the EFA. Item reduction was informed by item correlation, by the qualitative data collected during item creation, and professional decision making; the items which were considered to be most representative of the concept were retained. To facilitate the EFA, principal axis factoring was used for extraction with Promax rotation used to account for correlation among factors. ${ }^{17}$ The number of factors included were chosen with consideration of the proportion of variance explained by each factor, viz: number of eigenvalues greater than one and clinical interpretation of factors. Once the factors were determined, they were reviewed by First Nations health professionals $(n=5)$ who independently evaluated the relevance and applicability of the factors as domains of child HR-QoL.

\section{Reliability and validity}

Cronbach's alpha was used to examine internal consistency and intraclass correlation (ICC) was used to assess test-retest reliability when the survey was repeated by participants 4 weeks later. Internal scale reliability refers to the correlation of the items within the scale. ${ }^{18}$

To evaluate construct validity, Pearson's correlation was used to examine the correlations between the FirstNations-CQoL domains and comparative measures. Construct validity refers to how a survey correlates to other surveys with similar (convergent) and dissimilar (divergent) constructs. ${ }^{18}$ For instance, we would expect the FirstNations-CQoL to be moderately correlated to the established Paediatric QoL Inventory $4.0\left(\right.$ PedsQL $\left.^{4.0}\right)$ and weakly correlated to the Spence Anxiety scale. Pearson coefficients of 0.7 were considered strong, 0.4-0.6 moderate and $\leq 0.3$ weak. ${ }^{19}$ Data were analysed using SPSS (SPSS Statistics for Windows, V.25.0, IBM) and R (R Core Team, V.3.6.3, www.r-project.org).

Descriptive statistics were produced for all demographic characteristics and are presented using means and SD for data that were normally distributed and medians and IQR for non-parametric data. Missing data in the scales were imputed using the expectation-maximisation algorithm to preserve relationships between variables. ${ }^{20}$

\section{RESULTS}

\section{Baseline characteristics}

Of the 335 potential participants screened, 263 were enrolled. Of these, 3 withdrew (due to other commitments) and 97 did not return the survey (lost to follow-up), leaving 163 who completed the baseline survey. Of the 163,46 repeated the survey 4 weeks later. The demographic characteristics of the parent/carer and child are presented in table 1 . The majority $(87.1 \%)$ of participants were female and mothers $(79.7 \%)$ to the child for whom they were completing the survey; the median age of the children was 5.7 years, IQR 6.9.

\section{Identification of domains}

Twenty-one items were analysed using EFA resulting in five factors with eigenvalues greater than one explaining $63 \%$ of the total variance. However, models containing the four and five factor solutions did not converge, indicating a simpler three factor model was more appropriate, explaining $52 \%$ of the variation. The three latent factors reflected themes raised during item creation: quality of life, patient experience and patient support (table 2). The subscale correlations were weak to moderate: quality of life and patient experience $(\mathrm{r}=0.359, \mathrm{p}<0.001)$; quality of life and patient support $(\mathrm{r}=0.406, \mathrm{p}<0.001)$ and patient support and patient experience $(r=0.433, p<0.001)$, indicating low overlap between factors. There was a consensus from the panel of First Nations health professionals that these domains were representative of child HR-QoL.

\section{Reliability}

The novel HR-QoL tool demonstrated good internal consistency, with Cronbach's alpha coefficients of $\geq 0.7$ (Cronbach's alpha for quality of life $=0.808$; patient experience $=0.880$; patient support $=0.768$ ). Test-retest reliability was conducted with 45 participants. Good reliability was observed for the overall scale (ICC $\mathrm{r}=0.753 ; 95 \%$ CI: 0.593 to 0.856 ) and subscale reliability varied: quality of life (ICC r $=0.663$; 95\% CI:0.462 to 0.799), patient experience (ICC r $=0.744,95 \%$ CI:0.579 to 0.850 ) and patient support (ICC $\mathrm{r}=0.794 ; 95 \%$ CI:0.655 to 0.881 ) are displayed in table 3 .

\section{Validity}

The FirstNations-CQoL was moderately to strongly correlated to the PedsQL ${ }^{4.0}$, with Pearson's coefficients 
Table 1 Characteristics of participants at baseline and at 4-week follow-up

\begin{tabular}{lll}
\hline Characteristics & $\mathbf{N}=\mathbf{1 6 3}(\%)$ & $\mathbf{N}=\mathbf{4 6}(\%)$ \\
\hline $\begin{array}{ll}\text { Gender of children } \\
\text { Male }\end{array}$ & $101(61.9)$ & $30(65.2)$ \\
\hline Female & $61(37.4)$ & $16(34.8)$ \\
\hline Missing & $1(0.6)$ & 0 \\
\hline Age range of children & & \\
\hline Less than 24 months & $34(21.1)$ & $11(23.9)$ \\
\hline 2-4years & $38(23.6)$ & $11(23.9)$ \\
\hline 5-7years & $32(19.8)$ & $7(15.2)$ \\
\hline 8-12years & $57(35.4)$ & $17(37.0)$ \\
\hline Missing & $2(1.2)$ & 0 \\
\hline Gender of parents/carers & & \\
\hline Male & $21(12.8)$ & $5(10.9)$ \\
\hline Female & $142(87.1)$ & $41(89.1)$ \\
\hline
\end{tabular}

Age range of parents/carers

$\begin{array}{lll}\text { 18-25years } & 23(14.1) & 5(10.9) \\ \text { 26-35years } & 66(40.4) & 17(37.0) \\ \text { 36-45years } & 46(28.2) & 17(37.0) \\ 46+\text { years } & 24(14.7) & 7(15.1) \\ \text { Missing } & 4(2.4) & 0\end{array}$

Relationship to child

\begin{tabular}{|lll}
\hline Father & $17(10.4)$ & $3(6.5)$ \\
\hline Mother & $130(79.7)$ & $38(82.6)$ \\
\hline Relative/carer & $16(9.8)$ & $5(10.9)$ \\
\hline Care type at home & & \\
\hline Both parents & $87(53.3)$ & $26(56.5)$ \\
\hline Single parent & $46(28.2)$ & $12(26.1)$ \\
\hline Shared care/relative/carer & $18(11.0)$ & $6(13.0)$ \\
\hline Missing & $12(7.3)$ & $2(4.4)$ \\
\hline Employment status & & \\
\hline Full time & $41(25.1)$ & $14(30.4)$ \\
\hline Part time & $25(15.3)$ & $8(17.4)$ \\
\hline Casual & $11(6.7)$ & $5(10.9)$ \\
\hline Not in paid employment & $84(51.5)$ & $91(41.3)$ \\
\hline Missing & $2(1.2)$ & 0 \\
\hline Home location & & \\
\hline Major city & $108(66.2)$ & $38(82.6)$ \\
\hline Inner regional & $36(22.0)$ & $4(8.7)$ \\
\hline Outer regional/rural/remote & $17(10.4)$ & $4(8.7)$ \\
\hline Missing & $2(1.2)$ & 0 \\
\hline Indigenous status of parent/carer & & \\
\hline Aboriginal & $83(50.9)$ & $22(47.8)$ \\
\hline Torres Strait Islander & $8(4.9)$ & $2(4.3)$ \\
\hline Both & $9(5.5)$ & $2(4.3)$ \\
\hline Non-Indigenous & $53(32.5)$ & $19(41.3)$ \\
\hline Declined & $7(4.2)$ & $1(2.2)$ \\
\hline Missing & $3(1.8)$ & 0 \\
\hline
\end{tabular}

of $\mathrm{r}=0.681$ for ages $2-4$ years and $\mathrm{r}=0.651$ for ages $5-12$ years. Likewise, the KPDS $(r=-0.513)$ and independent assessment of HR-QoL (single-item scale) by parents was moderately correlated $(r=0.480)$ to the FirstNationsCQoL, suggesting acceptable convergent validity across the relative comparison measures. Divergent validity was not demonstrated against the Spence Anxiety Scales, the FirstNations-CQoL being moderately correlated to both the preschool $(\mathrm{r}=-0.466)$ and school age $(\mathrm{r}=-0.535)$ scales, presented in table 4 .

\section{DISCUSSION}

As far as we are aware, we have developed the first parent-proxy HR-QoL tool applicable to Australian First Nations children for use in clinical and research settings. In testing with 163 parents/carers of First Nations children in South-East Queensland, the tool demonstrated reliability (internal consistency, test-retest) and validity (convergent) for use with parents of First Nations children demographically similar to our study population.

We identified three domains and 21 questions (items) that reflected concepts of quality of life, patient experience and patient support. These domains were determined by evaluating which items correlated together via EFA and whether these groupings were logical and appropriate in terms of content from the perspective of First Nations health professionals. The domains of the FirstNations-CQoL are not typical domains of current Western-based HR-QoL, such as found in well-established proxy measures: PedsQL ${ }^{4.0},{ }^{11} \mathrm{KINDL}^{\mathrm{R} 21}$ and the Child Health Questionnaire. ${ }^{22}$ In these established HR-QoL measures, the domains reflect individual functioning as it relates to physical, mental and social well-being. ${ }^{23}$ For example, the widely used PedsQL ${ }^{4.0}$ has four domains: (1) physical functioning, (2) emotional functioning, (3) social functioning and (4) school functioning. ${ }^{11}$ The items included in these domains query the functioning of the individual, that is, 'In the past month, how much of a problem has your child had bathing. ${ }^{11}$ The FirstNationsCQoL also includes items related to individual functioning in the quality of life domain, however it differs to the PedsQL ${ }^{4.0}$ and others mentioned, in that it also considers the wider health environment that influences and can facilitate human function, such as a person's interactions with the health system (patient experience domain) and/or whether they have support (patient support domain).

In the patient experience domain, the questions relate to the respondent's perceptions of health information, the delivery of that information and whether respondents feel they have adequate information. Although feeling informed and knowledgeable about one's health is valued generally, it is perhaps more important for First Nations people in terms of HR-QoL. ${ }^{24}$ This is because the colonial process has undermined First Nations people's autonomy and access to culturally relevant and safe healthcare. ${ }^{2}$ Qualitative studies ${ }^{725-29}$ demonstrate that First Nation's 
Table 2 Results of exploratory factor analysis: item means with SD and factor loadings

\begin{tabular}{lccrc}
\hline Items & Mean (SD) & $\begin{array}{c}\text { Patient } \\
\text { experience }\end{array}$ & QOL & $\begin{array}{c}\text { Patient } \\
\text { support }\end{array}$ \\
\hline Felt respected by medical staff & $3.08(0.87)$ & $\mathbf{0 . 8 1 1}$ & -0.134 & 0.000 \\
\hline Felt like you had enough information & $2.97(0.95)$ & $\mathbf{0 . 7 7 4}$ & 0.093 & -0.083 \\
\hline Felt like your child's health situations were well explained & $3.14(0.90)$ & $\mathbf{0 . 7 7 1}$ & -0.020 & 0.045 \\
\hline The medical staff listen to you & $2.94(0.91)$ & $\mathbf{0 . 7 4 9}$ & 0.064 & -0.086 \\
\hline Felt like medical staff are there to help you & $3.12(0.88)$ & $\mathbf{0 . 6 7 3}$ & -0.116 & 0.193 \\
\hline The medical staff don't believe you & $2.96(1.05)$ & $\mathbf{0 . 6 5 6}$ & 0.028 & -0.019 \\
\hline Felt frustrated & $2.02(1.06)$ & $\mathbf{0 . 5 6 7}$ & 0.197 & -0.240 \\
\hline You could ask medical staff questions if you needed to & $3.45(0.81)$ & $\mathbf{0 . 5 4 7}$ & -0.031 & 0.197 \\
\hline You could teach your family about your child's health needs & $3.41(0.85)$ & $\mathbf{0 . 4 4 6}$ & 0.044 & 0.219 \\
\hline You have enough knowledge to care for your child when they are & $3.51(0.76)$ & $\mathbf{0 . 3 5 2}$ & -0.007 & 0.076 \\
sick & & & & -0.048 \\
\hline Spend time with family as usual & $3.20(0.97)$ & 0.018 & $\mathbf{0 . 8 3 8}$ & -0.024 \\
\hline Do activities they enjoy & $3.03(0.95)$ & 0.052 & $\mathbf{0 . 7 6 5}$ & 0.208 \\
\hline Felt strong/good/deadly & $2.89(1.00)$ & -0.043 & $\mathbf{0 . 6 8 7}$ & -0.089 \\
\hline Go to school/day care & $2.89(1.27)$ & 0.013 & $\mathbf{0 . 5 7 9}$ & -0.141 \\
\hline Had very little energy & $2.49(1.19)$ & 0.087 & $\mathbf{0 . 5 3 5}$ & 0.231 \\
\hline Slept through the night & $2.76(1.32)$ & -0.089 & $\mathbf{0 . 4 8 5}$ & 0.196 \\
\hline Eating as normal & $2.86(1.16)$ & -0.108 & $\mathbf{0 . 4 5 9}$ & 0.007 \\
\hline Been extra clingy & $1.99(1.12)$ & 0.058 & $\mathbf{0 . 3 2 9}$ & $\mathbf{0 . 7 6 3}$ \\
\hline There is someone you can trust to provide childcare if you are & $3.00(1.18)$ & 0.026 & -0.043 & $\mathbf{0 . 7 1 6}$ \\
\hline away & & & $\mathbf{0 . 5 9 2}$ \\
\hline Your family could manage your child's health if they needed to & $2.84(1.14)$ & -0.046 & 0.060 & 0.042 \\
\hline You could call someone if you are struggling & $3.24(1.00)$ & 0.189 & & \\
\hline
\end{tabular}

Extraction method: principal axis factoring. Rotation Method: promax with Kaiser normalisation. a. Rotation converged in five iterations.

QOL, quality of life.

parents and carers experience considerable barriers to health literacy and self-efficacy in engaging with the health system to manage child illness which has implications for healthcare utilisation and parent and child wellbeing. Baba $e t a l$ s work with Aboriginal Medical Services highlights how insufficient information and inadequate support from mainstream health services can leave First Nations patients feeling scared, confused and alone. ${ }^{30}$ These experiences are likely to inform child HR-QoL as parents act on their behalf in navigating the health system.

Similarly, in the patient support domain, the questions relate to whether the respondent feels supported in their home environment. It is well established that family and community play a central role in how First Nations people define health and well-being. ${ }^{2}$ Yet many social factors can affect the capacity of traditional family support networks, ${ }^{30}$ which in turn affects how families are able to cope with child health challenges. ${ }^{30-34}$ The relevance of these domains with respect to HR-QoL has been identified, both in our own qualitative investigations, ${ }^{7}$ and prior studies investigating how Australian First Nations people perceive health and well-being. ${ }^{25}{ }^{25}$ Moreover, 'having a support network' and 'experience of health services' are recognised components of quality of life as determined by the WHO's Quality of Life Instrument (WHO-QOL) manual. ${ }^{32}$ A content evaluation ${ }^{33}$ of available HR-QoL measures against the WHO-QOL criteria suggests that many tools were created prior to establishing the differences between individual function and HR-QoL and as such do not adequately reflect HR-QoL in its holistic definition. Acceptance of the First Nations-CQoL at face value by parents and health professionals, and demonstrated convergent validity with the comparison measures, suggest that the incorporation of these domains into future culturally-specific HR-QoL measures is important and worthwhile.

This study provides insight into culturally specific psychometrics for First Nations Australians. An HR-QoL tool, such as the FirstNations-CQoL could be utilised in primary and hospital health settings to inform patient experience and treatment efficacy (in the context of improving HR-QoL). These types of measures are typically quick to complete, can be facilitated using a paper and pen or electronically 
Table 3 Internal reliability and test-retest reliability of FirstNations-CQoL scale and scale domains against comparison measures: single-item HR-QoL, KPDS, PedsQL ${ }^{4.0}$ and SCAS-P

\begin{tabular}{|c|c|c|c|c|c|c|c|c|c|}
\hline \multirow[b]{2}{*}{ Measures } & \multicolumn{4}{|c|}{ Baseline scores } & \multicolumn{4}{|c|}{ 4-week follow-up } & \multirow{2}{*}{$\begin{array}{l}\text { Test-retest } \\
\text { ICC }\end{array}$} \\
\hline & $\mathbf{N}$ & Mean & SD & $\begin{array}{l}\text { Cronbach's } \\
\text { alpha }\end{array}$ & $\mathbf{N}$ & Mean & SD & $\begin{array}{l}\text { Cronbach's } \\
\text { alpha }\end{array}$ & \\
\hline $\begin{array}{l}\text { FirstNations-CQoL } \\
\text { Total (21-items) }\end{array}$ & 152 & 61.81 & 11.72 & 0.880 & 45 & 64.49 & 11.39 & 0.876 & 0.753 \\
\hline $\begin{array}{l}\text { FirstNations-CQoL } \\
\text { Quality of Life }\end{array}$ & 152 & 22.12 & 5.91 & 0.808 & 45 & 23.39 & 5.60 & 0.818 & 0.663 \\
\hline $\begin{array}{l}\text { FirstNations-CQoL } \\
\text { Patient Experience }\end{array}$ & 152 & 30.61 & 6.31 & 0.880 & 45 & 31.68 & 6.68 & 0.873 & 0.744 \\
\hline $\begin{array}{l}\text { FirstNations-CQoL } \\
\text { Patient Support }\end{array}$ & 152 & 9.08 & 2.75 & 0.768 & 45 & 9.42 & 2.52 & 0.766 & 0.794 \\
\hline Single item HR-QoL* & 157 & 7.61 & 2.13 & NA & 45 & 8.13 & 1.89 & NA & 0.545 \\
\hline Kessler Scale & 161 & 19.86 & 8.09 & 0.937 & 45 & 19.11 & 7.40 & 0.929 & 0.812 \\
\hline PedsQL aged 5-12 & 83 & 57.74 & 20.15 & 0.931 & 23 & 62.15 & 16.43 & 0.899 & 0.798 \\
\hline PedsQL aged 2-4 & 36 & 75.33 & 18.12 & 0.919 & 23 & 76.06 & 16.57 & 0.897 & 0.938 \\
\hline Spence preschool & 36 & 20.96 & 12.74 & 0.845 & 11 & 18.82 & 14.09 & 0.881 & 0.897 \\
\hline Spence school aged & 74 & 25.18 & 18.24 & 0.947 & 23 & 23.33 & 13.99 & 0.908 & 0.806 \\
\hline
\end{tabular}

*Parent rating of child HR-QoL using single numerical scale

FirstNations-CQoL, First Nations-Child Quality of Life; HRQoL, health-related quality of life; KPDS, Kessler Psychological Distress Scale; NA, not available; PedsQL ${ }^{4.0}$, Paediatric QoL Inventory 4.0.

and provide insight into subjective experiences that are challenging to quantify. A strength of the study has been the consultative approach taken to develop the tool; item development was informed by First Nations people's conceptualisations of HR-QoL and subsequently checked for acceptability by a wider population. The findings contribute to the growing understanding of what Australian First Nations families value in terms of HR-QoL and how those values can be evaluated in a health setting. Yet, the project is not without limitations. Demographic information on those who enrolled but did not complete the survey was unavailable. Thus, we are unable to comment on what factors (eg, socio-economic status) may have influenced participation. Demographic information for those who did participate is varied; as is the demographic information for those who participated in the follow-up survey with the exception of 'location', with more participants from a major city completing the follow-up. This is unsurprising given the impact of travel to the hospital on family time and capacity. Additionally, while participants were offered assistance

Table 4 Construct validity of FirstNations-CQoL against comparison measures: single-item HR-QoL, PedsQL ${ }^{4.0}$ ages 2-4 years, PedsQL ${ }^{4.0}$ ages 5-12 years, KPDS and SCAS-P

\begin{tabular}{|c|c|c|c|c|c|c|c|}
\hline $\begin{array}{l}\text { Pearson's } \\
\text { correlation }\end{array}$ & $\begin{array}{l}\text { FirstNations-CQoL } \\
\text { Total }\end{array}$ & $\begin{array}{l}\text { Single-item } \\
\text { HR-QoL }\end{array}$ & $\begin{array}{l}\text { PedsQL } \\
\text { aged } \\
5-12\end{array}$ & $\begin{array}{l}\text { PedsQL } \\
\text { aged 2-4 }\end{array}$ & $\begin{array}{l}\text { Kessler } \\
\text { scale }\end{array}$ & $\begin{array}{l}\text { Spence } \\
\text { school age }\end{array}$ & $\begin{array}{l}\text { Spence } \\
\text { preschool }\end{array}$ \\
\hline $\begin{array}{l}\text { FirstNations-CQoL } \\
\text { Total }\end{array}$ & 1 & $0.480^{*}$ & $0.651^{*}$ & $0.681^{*}$ & $-0.513^{*}$ & $-0.535^{*}$ & $-0.466^{\star}$ \\
\hline Single-item HR-QoL & $0.480^{*}$ & 1 & $0.392^{*}$ & $0.518^{*}$ & $-0.389^{*}$ & $-0.304^{*}$ & -0.264 \\
\hline PedsQL aged 5-12 & $0.651^{*}$ & $0.392^{*}$ & 1 &.$b$ & $-0.498^{*}$ & $-0.707^{*}$ &.$b$ \\
\hline PedsQL aged 2-4 & $0.681^{*}$ & $0.518^{\star}$ &.$b$ & 1 & $-0.385 \dagger$ &.$b$ & $-0.548^{*}$ \\
\hline Kessler Scale & $-0.513^{*}$ & $-0.389^{*}$ & $-0.498^{*}$ & $-0.385 \dagger$ & 1 & $0.492^{*}$ & 0.275 \\
\hline Spence Pre-school & $-0.466^{*}$ & -0.264 &.$b$ & $-0.548^{\star}$ & 0.275 &.$b$ & 1 \\
\hline Spence School-age & $-0.535^{\star}$ & $-0.304^{*}$ & $-0.707^{\star}$ &.$b$ & $0.492^{*}$ & 1 & .b \\
\hline
\end{tabular}

b. Cannot be computed because at least one of the variables is constant.

${ }^{*}$ Correlation is significant at the 0.01 level (two tailed).

†Correlation is significant at the 0.05 level (two tailed).

FirstNations-CQoL, First Nations-Child Quality of Life; HRQoL, health-related quality of life; KPDS, Kessler Psychological Distress Scale;

PedsQL ${ }^{4.0}$, Paediatric QoL Inventory 4.0; SCAS, Spence Children's Anxiety Scale. 
to complete the survey if they required it, we are unable to comment on whether literacy levels would have been a deterrent to participation as the vast majority of participants were able to complete the survey without assistance and did not indicate literacy as a barrier. In removing excess items prior to the EFA, it is possible that the results are biased to the researchers. However, the alignment of the resulting domains with the preceding qualitative investigation suggest that the relevant constructs have been adequately represented. Second, given there are no age-appropriate comparison scales for infants age $0-2$ years, we combined the infants with children aged 2-4 for comparison to the other measures. While this approach has shown sound psychometric properties in our study, we are unable to distinguish the sensitivity for babies in particular. Likewise, we have been unable to demonstrate divergent validity to the Spence Anxiety Scale. This is likely because several items within the FirstNations-CQoL relate to anxiety. Future research should consider other comparison measures. However, cultural and age appropriate proxy measures for comparison remain limited and there is a dearth of psychometric tools validated for First Nations Australians generally. ${ }^{5}$ A focus of future research should be to evaluate the psychometric properties of the tool with specific disease groups and disease-specific items.

There is evidence to suggest that the values of Australian First Nations people are not being adequately represented in available HR-QoL measures. ${ }^{3}$ We have developed a culturally specific HR-QoL measure which has been conceptualised using Australian First Nations values of HR-QoL, which is acceptable for use and relative to other HR-QoL measures. Future research should expand on the further evaluation of the novel measure with larger and disease-specific populations, as well as evaluate its sensitivity when used to evaluate treatment.

\section{Author affiliations}

${ }^{1}$ Institute of Health \& Biomedical Innovation, Queensland University of Technology QUT, Brisbane, Queensland, Australia

${ }^{2}$ School of Psychology, The University of Queensland, Saint Lucia, Queensland, Australia

${ }^{3}$ Department of Respiratory Medicine, Queensland Children's Hospital, South Brisbane, Queensland, Australia

${ }^{4}$ Child Health Division, Menzies School of Health Research, Darwin, Queensland, Australia

${ }^{5}$ Faculty of Health, Queensland University of Technology, Brisbane, Queensland, Australia

${ }^{6}$ Menzies Health Institute Queensland and School of Dentistry and Oral Health, Gold Coast Campus - Griffith University, Gold Coast, Queensland, Australia

${ }^{7}$ Faculty of Dentistry, Oral and Craniofacial Sciences, King's College London, London, UK

${ }^{8}$ Queensland Children's Hospital, South Brisbane, Queensland, Australia

${ }^{9}$ Faculty of Medicine, The University of Queensland, Herston, Queensland, Australia

Acknowledgements We dedicate this paper to the memory of our dear friend and co-author, Anna Maria Bell. You are missed and remembered. We thank the many families and health professionals who generously provided their time and feedback on this study.

Contributors PN, ABC, JS, KOG, MT and KB all contributed to the study conception and design. $K B, A B$ and $G R$ were responsible for data collection and $K B$ and $L J$ undertook the analysis. The manuscript was drafted by $K B$ and $K O G$, and $A C, J S$,
$\mathrm{NJ}, \mathrm{MT}$ and LJ contributed to the content and revision of the manuscript. All authors read and approved the final version.

Funding This work was supported by the Queensland Children's Hospital Foundation under grant no. 50227 and the NHMRC Centre for Research Excellence in Respiratory Health of Aboriginal and Torres Strait Islander Children (grant 1040830). AC is supported by Australia's National Health and Medical Research Council (NHMRC) Practitioner Fellowship (1058213) and a Children's Hospital Foundation Queensland (50286) top-up fellowship.

Competing interests None declared.

Patient and public involvement Patients and/or the public were involved in the design, or conduct, or reporting, or dissemination plans of this research. Refer to the Methods section for further details.

Patient consent for publication Not required.

Ethics approval Ethical approval was granted by the Queensland Children's Hospital and Health Service Human Research Ethics Committee (HREC/18/ QCHQ/44186); Queensland University of Technology's University Human Research Ethics Committee (1800001262) and the University of Queensland Human Research Ethics Committee (2018002613).

Provenance and peer review Not commissioned; externally peer reviewed.

Data availability statement Study data may be made available on request with the appropriate human research ethics committee approval and with the consent of the participating community as required by Australian criteria for research within First Nations communities. As the survey has yet to undergo final validation processes, it is not ready for general use or adaptation. However, those wishing to access the survey are welcome to contact kaley.butten@hdr.qut.edu.au to discuss context of use and potential access.

Open access This is an open access article distributed in accordance with the Creative Commons Attribution Non Commercial (CC BY-NC 4.0) license, which permits others to distribute, remix, adapt, build upon this work non-commercially, and license their derivative works on different terms, provided the original work is properly cited, appropriate credit is given, any changes made indicated, and the use is non-commercial. See: http://creativecommons.org/licenses/by-nc/4.0/.

\section{ORCID iDs}

Kaley Butten http://orcid.org/0000-0001-6100-8469

Kerry-Ann F 0'Grady http://orcid.org/0000-0002-8159-2620

\section{REFERENCES}

1 The World Health Organization Quality of Life Assessment Group. The world Health organization quality of life assessment (WHOQOL): position paper from the world Health organization. Soc Sci Med 1995;41:1403-9.

2 ButlerTL, AndersonK, GarveyG. Aboriginal and Torres Strait Islander people's domains of wellbeing: a comprehensive literature review. Soc Sci Med 2019;2019:138-57.

3 Angell B, Muhunthan J, Eades A-M, et al. The health-related quality of life of Indigenous populations: a global systematic review. Qual Life Res 2016;25:2161-78.

4 Davy C, Kite E, Sivak L, et al. Towards the development of a wellbeing model for Aboriginal and Torres Strait Islander peoples living with chronic disease. BMC Health Serv Res 2017;17:659.

5 Le Grande M, Ski CF, Thompson DR, et al. Social and emotional wellbeing assessment instruments for use with Indigenous Australians: a critical review. Soc Sci Med 2017;187:164-73.

6 Newton D, Day A, Gillies C, et al. A review of Evidence-based evaluation of measures for assessing social and emotional well-being in Indigenous Australians. Aust Psychol 2015;50:40-50.

7 ButtenK, NewcombePA, ChangAB. Concepts of health-related quality of life of Australian Aboriginal and Torres Strait Islander children: parent perceptions. Appl Res Qual Life 2020;4.

8 Eiser C, Varni JW. Health-Related quality of life and symptom reporting: similarities and differences between children and their parents. Eur J Pediatr 2013;172:1299-304.

9 Polit DF, Beck CT. The content validity index: are you sure you know what's being reported? critique and recommendations. Res Nurs Health 2006;29:489-97.

10 Yiengprugsawan V, Kelly M, Tawatsupa B. Kessler psychological distress scale. In: Michalos AC, ed. Encyclopedia of quality of life and wellbeing research. Dordrecht: Springer Netherlands, 2014: 3469-70.

11 Varni JW, Limbers CA, Burwinkle TM. Parent proxy-report of their children's health-related quality of life: an analysis of 13,878 
parents' reliability and validity across age subgroups using the PedsQL 4.0 generic core scales. Health Qual Life Outcomes 2007;5:2.

12 Nauta MH, Scholing A, Rapee RM, et al. A parent-report measure of children's anxiety: psychometric properties and comparison with child-report in a clinic and normal sample. Behav Res Ther 2004;42:813-39.

13 Spence SH, Rapee R, McDonald C, et al. The structure of anxiety symptoms among preschoolers. Behav Res Ther 2001;39:1293-316.

14 Tsang S, Royse CF, Terkawi AS. Guidelines for developing, translating, and validating a questionnaire in perioperative and pain medicine. Saudi J Anaesth 2017;11:80.

15 Williamson A, Redman S, Dadds M, et al. Acceptability of an emotional and behavioural screening tool for children in Aboriginal community controlled health services in urban NSW. Aust N Z J Psychiatry 2010;44:894-900.

16 Yong AG. Pearce S. A beginner's guide to factor analysis: Focusing on exploratory factor analysis. Tutor Quant Methods Psychol 2013;2:79-94.

17 de Winter JCF, Dodou D. Factor recovery by principal axis factoring and maximum likelihood factor analysis as a function of factor pattern and sample size. J App/ Stat 2012;39:695-710.

18 Lapin BR. Considerations for reporting and reviewing studies including health-related quality of life. Chest 2020;158:S49-56.

19 Zumbo BD, Padilla JL. The Interplay Between Survey Research and Psychometrics, with a Focus on Validity Theory. In: Beatty P, Collins D, Kaye L, et al, eds. Advances in Questionnaire Design, Development, Evaluation and Testing, 2019: 593-612.

20 Enders CK. Using the expectation maximization algorithm to estimate coefficient alpha for scales with item-level missing data. Psychol Methods 2003;8:322-37.

21 Erhart M, Ellert U, Kurth B-M, et al. Measuring adolescents' HRQoL via self reports and parent proxy reports: an evaluation of the psychometric properties of both versions of the KINDL-R instrument. Health Qual Life Outcomes 2009;7:77.

22 Drotar D, Schwartz L, Palermo TM. Factor structure of the child health questionnaire-parent form in pediatric populations. J Pediatr Psychol 2001;31:2019;127-138.
23 Germain N, Aballéa S, Toumi M. Measuring the health-related quality of life in young children: how far have we come? J Mark Access Health Policy 2019;7:1618661.

24 Fayed N, de Camargo OK, Kerr E, et al. Generic patient-reported outcomes in child health research: a review of conceptual content using World Health organization definitions. Dev Med Child Neurol 2012;54:1085-95.

25 Meiklejohn JA, Arley B, Bailie R, et al. Community-identified recommendations to enhance cancer survivorship for Aboriginal and Torres Strait Islander people. Aust J Prim Health 2018;24:233-40.

26 Butten K, Johnson NW, Hall KK, et al. Impact of oral health on Australian urban Aboriginal and Torres Strait Islander families: a qualitative study. Int J Equity Health 2019;18:34.

27 Butten K, Johnson NW, Hall KK, et al. Yarning about oral health: perceptions of urban Australian Aboriginal and Torres Strait Islander women. BMC Oral Health 2020;20:1-12.

28 Durey A, McAullay D, Gibson B. Oral health in young Australian Aboriginal children: qualitative research on parents' perspectives. JDR Clin Trans Res 2017;2:38-47.

29 D'Sylva P, Walker R, Lane M, et al. Chronic wet cough in Aboriginal children: it's not just a cough. J Paediatr Child Health 2019;55:833-43.

30 Baba JT, Brolan CE, Hill PS. Aboriginal medical services cure more than illness: a qualitative study of how Indigenous services address the health impacts of discrimination in Brisbane communities. Int $J$ Equity Health 2014;13:56.

31 Sherwood J. Colonisation - it's bad for your health: the context of Aboriginal health. Contemp Nurse 2013;46:28-40.

32 Fisher HR. The needs of parents with chronically sick children: a literature review. J Adv Nurs 2001;36:600-7.

33 The World Health Organization Quality of Life Assessment Group. The world Health organization quality of life assessment (WHOQOL): development and general psychometric properties. Soc Sci Med 1998;46:1569-85.

34 Priest N, Mackean T, Davis E, et al. Strengths and challenges for Koori kids: harder for Koori kids, Koori kids doing well - exploring Aboriginal perspectives on social determinants of Aboriginal child health and wellbeing. Health Sociology Review 2012;21:165-79. 